$\mathrm{SCIDOC}$

International Journal of Dentistry and Oral Science (IJDOS)

ISSN: 2377-8075

\title{
Association Between Amount Of Remaining Tooth Structure And Tooth Morphology In Post Selection. - An Institution Based Retrospective Study
}

Research Article

Trinaina Somas Kandhan ${ }^{1}$, Iffat Nasim² ${ }^{2 *}$ Arvina Rajasekar ${ }^{3}$

${ }^{1}$ Saveetha Dental College and Hospital, Saveetha Institute of Medical and Technical Science, Saveetha University, India.

${ }^{2}$ Professor, Department of Conservative Dentistry and Endodontics, Saveetha Dental College and Hospital, Saveetha Institute Of Medical and Technical Science, Saveetha University, India.

${ }^{3}$ Senior Lecturer, Department of Periodontics, Saveetha Dental College and Hospitals, Saveetha Institute of Medical and Technical Sciences Saveetha University, Chennai, India.

\section{Abstract}

The lifespan of an endodontically involved tooth has been greatly influenced by continued emergence of different modalities in endodontic treatment and the restorative procedures.In the last few years, various prefabricated posts systems have emerged. The selection of a suitable post design and type is important, as it may have an influence on the survival of the tooth. Teeth have characteristic morphology and have many anatomical variations, which may adversely affect the selection and placement of a post. This study aims to assess the correlation between the amount of remaining tooth structure and tooth morphology during post selection.

A retrospective cross-sectional study was conducted using the patient records from the Department of Conservative Dentistry and Endodontics from June 2019-April 2020. The patients were assessed based on the type of post used, the remaining tooth structure and type of tooth/tooth morphology. Data was collected and then subjected to statistical analysis. A total of 714 patients, it was observed that 60 patients underwent post endodontic treatment with custom made posts, 334 patients with Prefabricated Fiber reinforced posts and 320 patients with Prefabricated Metal posts. $24.4 \%$ of the cases had a remaining tooth structure between $1-2 \mathrm{~mm}, 66.1 \%$ cases between $2-4 \mathrm{~mm}$ and $9.1 \%$ of the cases had a between $4-6 \mathrm{~mm}$. It was noticed that 40 year old patients mostly underwent post endodontic treatment and usually upper right maxillary central incisors were subjected to post endodontic restorative therapy. On statistical evaluation it was noticed that there was a positive correlation between remaining tooth structure and type of post used with a statistically significant result, $\mathrm{p}<0.05$.

For restored endodontically treated teeth that do not have complete circumferential tooth structure between the core and preparation finish line, the location of the remaining coronal tooth structure may affect their fracture resistance.Therefore it is of paramount importance that the analysis between types of post to be selected depending on the amount of tooth structure should be further studied so as to provide clarity to dentists during treatment planning of post endodontic restorations.

Keywords: Custommade Post; Post Endodontic Restoration; Prefabricated FRC Post; Prefabricated Metal Post; Remaining Tooth Structure.

\section{Introduction}

Restoration of endodontically treated teeth is an important aspect of dental practice that involves a range of treatment options of variable complexity [28]. The challenge may be complicated by substantial loss of coronal tooth structure and the ability to predict restorative success [21]. The likelihood of survival of a pulpless tooth is directly related to the quantity and quality of the remaining dental tissue. A post is usually placed in an attempt to strengthen the tooth. However, in vitro and in vivo studies have demonstrated that a post does not reinforce endodontically treated teeth. Posts are required for supporting a core founda-

\footnotetext{
*Corresponding Author:

Iffat Nasim,

Professor, Department of Conservative Dentistry and Endodontics, Saveetha Dental College and Hospital, Saveetha Institute Of Medical and Technical Science, Saveetha University, India.

Tel: +9199400636567

E-mail: iffatnasim@saveetha.com

Received: November 07, 2020

Accepted: November 22, 2020

Published: November 30, 2020

Citation: Trinaina Somas Kandhan, Iffat Nasim, Arvina Rajasekar. Association Between Amount Of Remaining Tooth Structure And Tooth Morphology In Post Selection. - An Institution Based Retrospective Study. Int J Dentistry Oral Sci. 2020;S10:02:0021:113-119. doi: http://dx.doi.org/10.19070/2377-8075-SI02-0100021
}

Copyright: Iffat Nasim ${ }^{\circ} 2020$. This is an open-access article distributed under the terms of the Creative Commons Attribution License, which permits unrestricted use, distribution and reproduction in any medium, provided the original author and source are credited. 
tion when there is insufficient clinical crown remaining [10, 13]. Nowadays, cast post-core restorations are the option of choice for endodontically treated teeth but this kind of restoration, according to many authors, makes teeth fragile and more susceptible to fracture. Prefabricated post systems have recently become increasingly popular because they can provide satisfactory results [5].

According to Cohen, et al.the association of prefabricated intraradicular posts, light-, chemical- and dual-cured resins, and dentin primers used for core build-up allows higher core preservation as well as adequate resistance.The use of prefabricated posts has brought special attention to core materials. This core build-up was designed to be made of composite, yet more specific materials have been developed [6]. It has been shown that composites have adequate resistance to compressive strength and fracture. With recent improvements in the bonding of composite resins to dentin, true internal support is now available. In 1998, Zalkind and Hochman recommended the use of composite as core material only when adequate coronal dentin structure is available [35].

There are various features that play an important role in selection of type of post to be used in post endodontic therapy such as, The length and shape of the remaining root determines the length of the post [8]. It has been suggested that root length should be considered for the selection of the ideal post length. It has been demonstrated that the greater the post length, the better the retention and stress distribution [2]. However, it may not always be possible to use a long post, especially when the remaining root is short or curved. Each tooth in the arch exhibits anatomic characteristics such as root curvature, mesio-distal width, and labio-lingual dimension. Hence, root anatomy dictates post selection [3]. Each tooth is anatomically different from the other and the same type of tooth may have certain variations, which may adversely affect the post placement. The amount of remaining coronal tooth structure is also a critical factor in determining the post selection [19].

Endodontically treated teeth often lack coronal tooth structure as a result of caries, previous restorations, trauma, or endodontic procedures [17]. In these situations, successful restoration of an endodontically treated tooth may be a challenging procedure.

This study aims to analyse the correlation between the remaining tooth structure and the post used so as to aid in the appropriate selection of posts during post endodontic therapy and thereby aid in efficient treatment planning.

\section{Materials And Methods}

\section{Study design and setting}

This institution based retrospective study examined the records of patients from June 2019-April 2020 undergoing treatment at our hospital. The approval from the institutional ethics committee was obtained. The sample population included patients who underwent post endodontic restorative therapy at the Outpatient ward of our hospital by means of non-probability sampling. Patients who were systemically healthy and were included in the study, those with mental and physical disabilities were excluded from the study.

\section{Data collection}

Data was obtained from exclusive patient management records which was used to identify 714 patients in the hospital database who underwent post endodontic replacement therapy using different types of posts, namely Custom made posts, Prefabricated FRC post and Prefabricated Metal posts. Data relevant to the study such as Patients unique ID, Name, Age, Sex, Tooth Number and Remaining Tooth Structure was recorded. Repeated patient records and incomplete records were excluded. Data was verified by an external reviewer.

\section{Statistical analysis}

Data was recorded in Microsoft Excel 2016 (Microsoft Office 10) and later exported to the SPSS software for Windows (Version 20.0, SPSS Inc, IBM, Chicago Ill., USA) and subjected to statistical analysis. Chi square test was employed with significance level set at $\mathrm{p}<0.005$.

\section{Results And Discussion}

In the present study, the final data comprised of 714 patients in total of Indian origin who underwent post endodontic restorative therapy, out of which, it was observed that 60 patients underwent post endodontic treatment with custom made posts, 334 patients underwent post endodontic treatment with Prefabricated Fiber reinforced posts and 320 patients underwent post endodontic treatment with Prefabricated Metal posts. (Table 1,Graph 1)

This table indicates that 60 patients underwent post endodontic treatment with custom made posts, 334 patients underwent post endodontic treatment with Prefabricated Fiber reinforced posts and 320 patients underwent post endodontic treatment with Pre-

Table 1. Frequency distribution of patients undergoing various post endodontic therapy.

\begin{tabular}{|c|c|c|c|c|c|}
\hline \multicolumn{2}{|c|}{} & Frequency & Percent & Valid Percent & Cumulative Percent \\
\hline \multirow{3}{*}{ Valid } & Custommade & 60 & 8.4 & 8.4 & 8.4 \\
\cline { 2 - 6 } & PrefabFRC & 334 & 46.8 & 46.8 & 55.2 \\
\cline { 2 - 6 } & PrefabMetal & 320 & 44.8 & 44.8 & 100 \\
\cline { 2 - 6 } & Total & 714 & 100 & 100 & \\
\hline
\end{tabular}


fabricated Metal posts.

On analysing the remaining tooth structure prevalence it was noticed that, $24.4 \%$ of the cases had a remaining tooth structure between $1-2 \mathrm{~mm}, 66.1 \%$ cases had a remaining tooth structure between $2-4 \mathrm{~mm}$ and $9.1 \%$ of the cases had a remaining tooth structure between 4-6 mm (Table 2, Graph 2).

This table indicates that out of 714 patients, $24.4 \%$ of the cases had a remaining tooth structure between $1-2 \mathrm{~mm}, 66.1 \%$ cases had a remaining tooth structure between $2-4 \mathrm{~mm}$ and $9.1 \%$ of the cases had a remaining tooth structure between 4-6 $\mathrm{mm}$.

It was also noticed that 40 year old patients mostly underwent post endodontic treatment and usually upper right maxillary central incisors (11) were subjected to post endodontic restorative therapy. (Graph 3, Graph 4)

In the present study, it was noted upon running Chi square tests of the correlation between the type of post used and tooth number that, there was positive correlation, the results were statistically significant $\mathrm{p}<0.05,(\mathrm{p}=0.00)$, thereby suggesting that type of tooth or tooth morphology played a predominant role in post selection. It was observed that Prefabricated FRC posts were preferred in cases of maxillary anterior teeth, followed by custom made posts. It was also observed that Prefabricated Metal posts were preferred in case of mandibular anteriors and posterior teeth.(Table 3, Graph 5)

Chi square test were done to correlate between the type of post used and the remaining tooth structure, it was observed that teeth with remaining tooth structure of $2-4 \mathrm{~mm}$ usually were treated with prefabricated FRC or Metal posts and those with 1-2mm of remaining tooth structure were subjected to therapy using Prefabricated FRC posts, the results were statistically significant $\mathrm{p}=0.043$ (Table 4, Graph 6)

On observing the above results, it was noticed that thorough plan-

\section{Graph 1. Frequency distribution of various post endodontic therapy.}

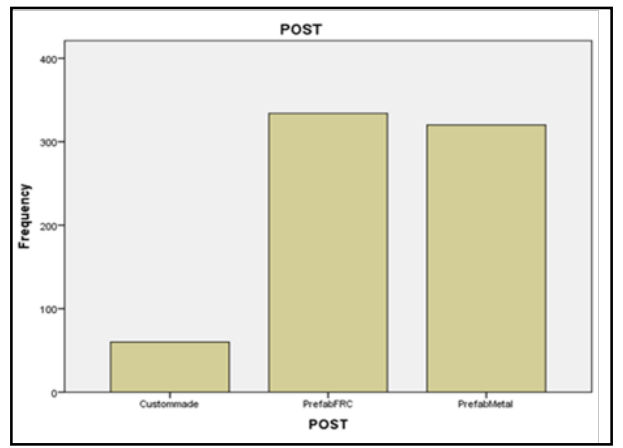

Graph 1. Bar graph depicts that 60 patients underwent post endodontic treatment with custom made posts, 334 patients underwent post endodontic treatment with Prefabricated Fiber reinforced posts and 320 patients underwent post endodontic treatment with

Prefabricated Metal posts.

Table 2. Frequency distribution of remaining tooth structure.

\begin{tabular}{|c|c|c|c|c|c|}
\hline \multicolumn{2}{|c|}{} & Frequency & Percent & Valid Percent & Cumulative Percent \\
\hline \multirow{3}{*}{ Valid } & 0 & 1 & 0.1 & 0.1 & 0.1 \\
\cline { 2 - 6 } & $1-2$ & 174 & 24.4 & 24.4 & 24.6 \\
\cline { 2 - 6 } & $2-4$ & 472 & 66.1 & 66.3 & 90.9 \\
\cline { 2 - 6 } & $4-6$ & 65 & 9.1 & 9.1 & 100 \\
\cline { 2 - 6 } & Total & 712 & 99.7 & 100 & \\
\hline Missing & System & 2 & 0.3 & & \\
\hline \multicolumn{6}{|c|}{ Total } \\
\hline
\end{tabular}

Graph 2. Frequency distribution of remaining tooth structure.

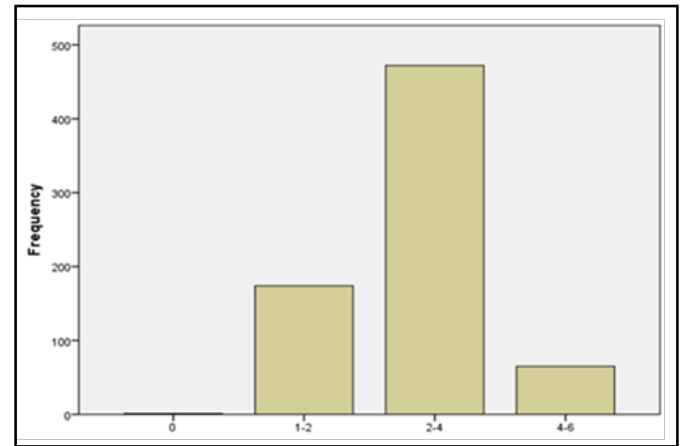

Graph 2:Bar graph depicts that out of 714 patients, $24.4 \%$ of the cases had a remaining tooth structure between $1-2 \mathrm{~mm}, 66.1 \%$ cases had a remaining tooth structure between $2-4 \mathrm{~mm}$ and $9.1 \%$ of the cases had a remaining tooth structure between $4-6 \mathrm{~mm}$. 
Graph 3. Frequency distribution of the age of patients.

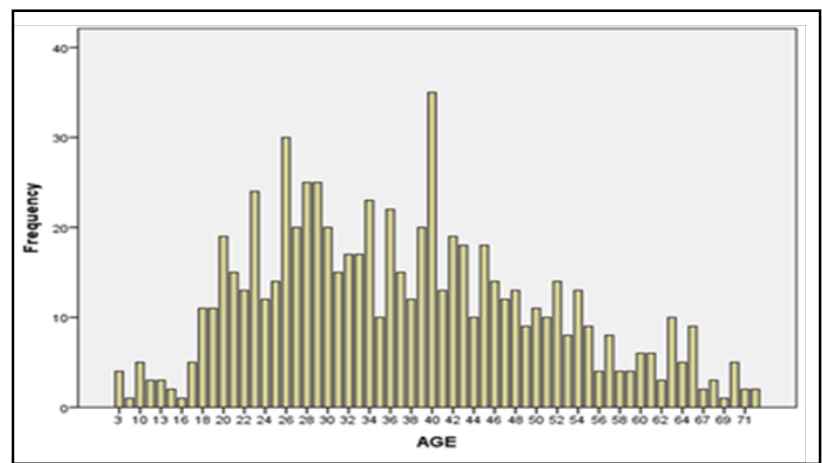

Graph 3: This graph depicts that 40 year old patients mostly underwent post endodontic treatment.

Graph 4. Frequency Distribution of type of tooth subjected to post endodontic therapy.

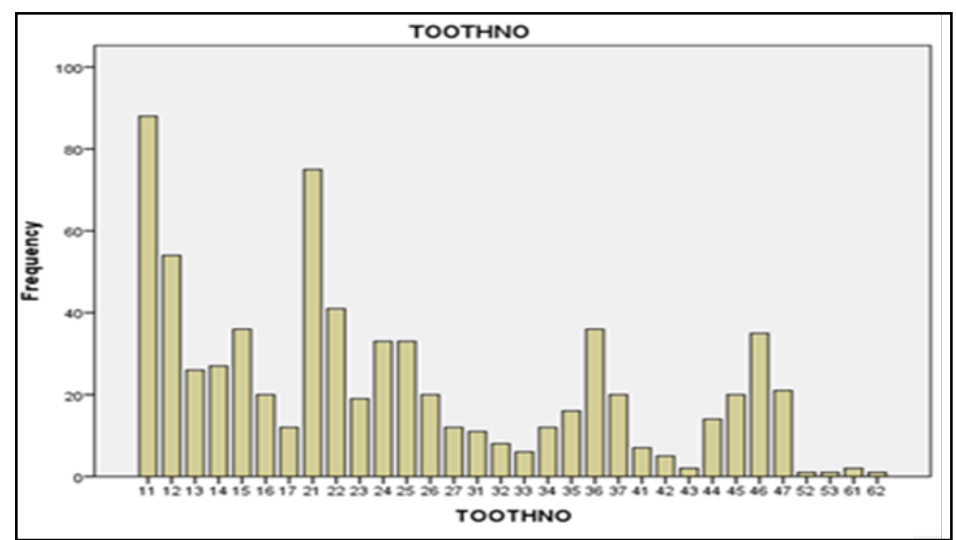

Graph 4: This graph depicts that usually upper right maxillary central incisors (11) was subjected to post endodontic restorative therapy.

Table 3. Statistical Analysis of correlation between tooth morphology and type of post used.

\begin{tabular}{|c|c|c|c|}
\hline & Value & df & Asymp. Sig. (2-sided) \\
\hline Pearson Chi-Square & $620.454^{\text {a }}$ & 62 & .000 \\
\hline Likelihood Ratio & 808.281 & 62 & .000 \\
\hline N of Valid Cases & 714 & & \\
\hline
\end{tabular}

This table indicates that on correlating tooth number or morphology with the type of post used, it was observed that there was a positive correlation, $\mathrm{p}=0.00$.

Graph 5. Association between tooth morphology/tooth number and the type of post used.

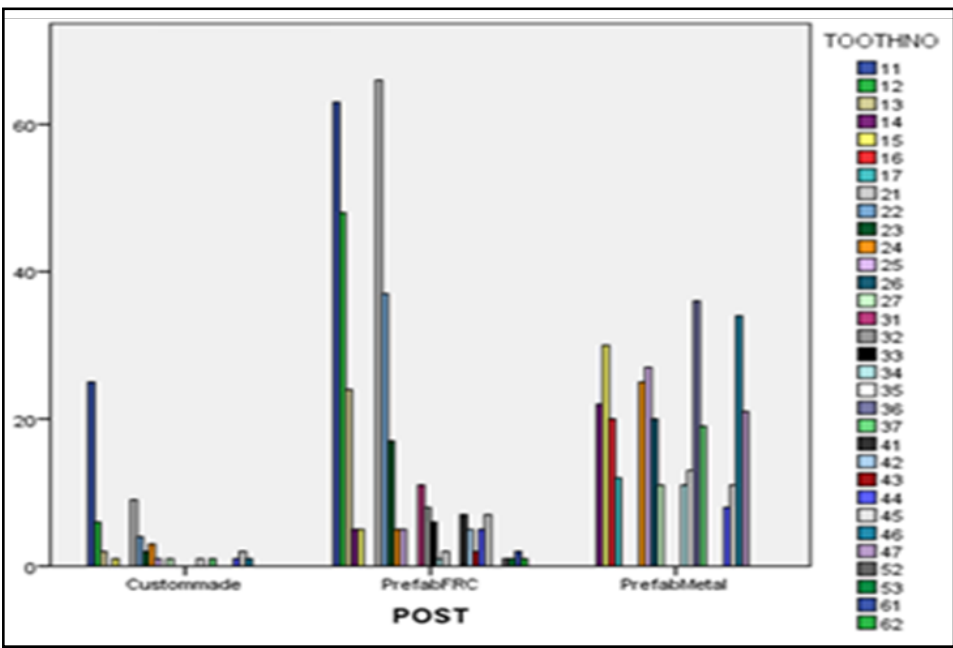

Graph 5: Bar graph depicting the association between the post design and the tooth morphology/ tooth number. X axis represents the type of post design and $\mathrm{Y}$ axis represents frequency of the particular tooth undergoing treatment with the chosen post design. There is a significant increase in the use of Prefabricated FRC posts in cases of maxillary anterior teeth.(Pearson Chi square value-0.000; $\mathrm{p}<0.05)$ 
Table 4. Statistical analysis of the correlation between remaining tooth structure and type of post used.

\begin{tabular}{|c|c|c|c|}
\hline & Value & df & Asymp. Sig. (2-sided) \\
\hline Pearson Chi-Square & $13.025^{a}$ & 6 & 0.043 \\
\hline Likelihood Ratio & 13.396 & 6 & 0.037 \\
\hline N of Valid Cases & 712 & & \\
\hline
\end{tabular}

This table indicates that on correlating the remaining tooth structure with the type of post used, it was observed that there was a positive correlation, $\mathrm{p}=0.043$.

Graph 6. Association between remaining tooth structure and type of post used.

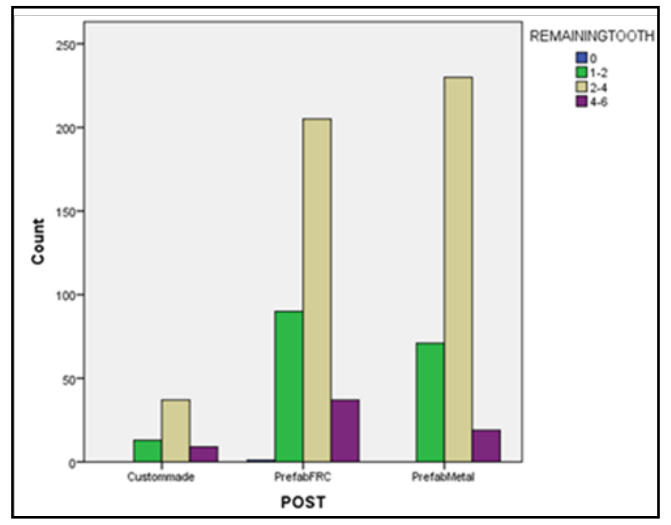

ning and understanding of tooth morphology and the remaining tooth structure forms the foundation for post endodontic therapy, and therefore, thorough knowledge regarding the indications and properties of different posts is of paramount importance.

Post and cores contribute in providing efficient restorative options for priorlyendodontically treated teeth. After reviewing various literature, it is observed that an ideal post system should have the following features:

(a) physical properties similar to that of the tooth's dentin,

(b) maximum retention with minimal dentin removal,

(c) distribution of various stresses evenly along the surface of the tooth and the root,

(d) esthetic compliance with the final restoration and the tissue surrounding it

(e) during placement and cementation, minimal stress should be dissipated,

(f) inability of the restoration to be displaced,

(g) proper retention of the core,

(h) easily retrievable if need be,

(i) material should be compatible with core,

(j) ease of use, safety and reliability, and

(k) reasonable cost.

Therefore, the clinician should be knowledgeable in selecting the right type of post and core systems to meet the biological, mechanical, and esthetic needs for each individual tooth [7].

One major cause of failure of the post endodontically restored tooth is usually root fracture.Therefore, it is of an advantage if tooth preparation and post designs minimize the chance of root fracture. A ferrule is a metal ring or cap intended for strengthening. A dental ferrule is an encircling band of cast metal around the coronal surface of the tooth. It has been noted that the use of a ferrule as a unit of the core or an artificial crown may be of vital importance in root canal filled teeth. The 'ferrule effect' occurs dueto the ferrule resisting various stresses such as functional lever forces, the wedging effect of tapered posts and the lateral forces exerted during the post insertion, the ferrule acts as a protective unit and is often referred to as the ferrule effect.

The restoration of endodontically treated teeth involves different materials and principles.Conservative preparations restricted to only endodontic access preparation can be restored using amalgam or composites associated with bonding agents to avoid microleakage. However, some posterior teeth whose greater amount of structure was missed need cuspal protection to direct forces at the long axis of the root, avoiding longitudinal fractures while anterior teeth often require post because of oblique forces.Even though posts are indicated to retain a core when coronal structure is missed, some authors have advocated the use of posts associated with composites as an alternative to crowns in posterior teeth [16].

Nevertheless, it is necessary to consider that there are metallic, ceramic and fiber posts, prefabricated or customized. Fiber posts have been indicated in situations where there is loss of root structure because its moduli of elasticity is close to dentin, but some coronal remaining structure is necessary to retain the core using adhesive systems. Different from these posts, metal cast posts have been used when greater quantities of coronal structure is missed and functional demand is higher such as support teeth of removable or fixed partial prostheses [31].

On observing, previously conducted invivo studies $[11,14,18$, 22-25, 29] and in vitro studies [12, 13, 15, 20, 26, 27, 34], regarding the conservative and endodontic considerations pertaining to post endodontic restorative therapy over the past few years, we have now focused on the epidemiology and prevalence pattern so as to analyze the current scenario and further elaborate on the possibility of the present diagnostic and treatment modalities to ultimately aid in efficient treatment planning. 
In this study it was noticed that Prefabricated Fibre Post and Core systems were preferred in comparison to other post endodontic systems and predominantly maxillary central incisors [11] were subjected to treatment with a remaining tooth structure of $2-4 \mathrm{~mm}$. This was further cross referenced with other epidemiological studies to further understand the relevance of the present study.

In a study by Spear et.al, he states that, to ensure functional longevity, endodontically treated teeth must have at least $5 \mathrm{~mm}$ of tooth structure coronal to the crestal bone. Three millimeters are needed to maintain a healthy soft tissue complex, and $2 \mathrm{~mm}$ of coronal tooth structure incisal to the preparation finish line are necessary to ensure structural integrity [32].

An in vitro study by $\mathrm{Al}$ Wahadani et.al, he compares the fracture resistance of adhesively cemented titanium, prefabricated, glass fiber, and carbon fiber posts on teeth with $2 \mathrm{~mm}$ of remaining tooth structure favored titanium posts. However, the teeth were not restored with crowns, negating the ferrule effect [1].

Another study by Gu et.al, compared metallic with nonmetallic posts cemented with adhesive or nonadhesive cements on teeth with $2 \mathrm{~mm}$ of remaining tooth structure. The authors concluded that fiber posts showed greater fracture resistance than cast posts and cores and that the use of resin cement did not improve the performance of metallic posts. This is in synchrony to the present study which reveals that Prefabricated Fiber reinforced posts are preferred in teeth with remaining tooth structure of $2-4 \mathrm{~mm}$ [9].

In a study by Sidoli et.al, [30] it was observed that the bulk of the tooth above the restorative margin should be at least 1.5 to 2 $\mathrm{mm}$ to achieve resistance form [30]. This was synonymous with this study where it was noted that $61.1 \%$ of the patients who were chosen for post endodontic restorative therapy had a remaining tooth structure of $2-4 \mathrm{~mm}$.

It was also found by Bergman et.al, that teeth restored with carbon fiber posts had inferior strength compared with those restored with metal posts when subjected to forces simulating those in a clinical setting. The use of cast post and cores in restoring endodontically treated teeth with moderate to severe coronal tooth loss [4]. This may be the reason attributing to Prefabricated Metal posts being a close competitor to Prefabricated FRC posts as a gold standard treatment of choice.

It was also observed in a study by Standlee st.al, [33] that nonmetal posts, such as a carbon fiber post system, can be used when ample coronal dentin remains and the crown supported by the remaining tooth structure; or, cast post and core is preferred in cases when there is minimal tooth structure or excessive tooth loss [33]. Although the present study varies from this school of thought, this may explain the reason for Prefabricated metal posts in posterior teeth in comparison to FRC posts, which thereby sheds light on the need for further exploration.

Endodontically treated teeth are more brittle due to loss of structural integrity associated with access preparation or caries. Because of the brittleness of these elements, planning will be associated with the remaining tooth structure and functional demands, once load received depends on tooth position in the arch, occlusion and rehabilitation planning. With the vast development and availability of different materials and post designs present for the restoration of teeth that have priorly undergone endodontic therapy, the operator must be selective in choosing the post system that is most suitable for the individual needs of each tooth. For restored endodontically treated teeth that do not have complete circumferential tooth structure between the core and preparation finish line, the location of the remaining coronal tooth structure may affect their fracture resistance.

Therefore it is of paramount importance that the analysis between types of post to be selected depending on the amount of tooth structure should be further studied so as to provide clarity to dentists during treatment planning of post endodontic restorations.

\section{Conclusion}

From the present study, it was observed that most patients underwent post endodontic treatment with Prefabricated Fiber reinforced posts followed by treatment with Prefabricated Metal posts. It was also noticed that the remaining tooth structure was between $2-4 \mathrm{~mm}$. It is concluded that restored endodontically treated teeth that do not have complete circumferential tooth structure between the core and preparation finish line, the location of the remaining coronal tooth structure may affect their fracture resistance and overall quality of post endodontic restoration. Further studies pertaining to the correlation between remaining tooth structure, tooth morphology and post selection will aid in efficient treatment planning..

\section{References}

[1]. Al-Wahadni AM, Hamdan S, Al-Omiri M, Hammad MM, Hatamleh MM. Fracture resistance of teeth restored with different post systems: in vitro study. Oral Surg Oral Med Oral Pathol Oral RadiolEndod. 2008 Aug;106(2):e77-83. Pubmed PMID: 18554954.

[2]. Baraban DJ. The restoration of endodontically treated teeth: an update. J Prosthet Dent. 1988 May;59(5):553-8. Pubmed PMID: 3290449.

[3]. Barkhordar RA, Radke R, Abbasi J. Effect of metal collars on resistance of endodontically treated teeth to root fracture. J Prosthet Dent. 1989 Jun;61(6):676-8. Pubmed PMID: 2657023.

[4]. Bergman B, Lundquist P, Sjögren U, Sundquist G. Restorative and endodontic results after treatment with cast posts and cores. J Prosthet Dent. 1989 Jan;61(1):10-5. Pubmed PMID: 2644413.

[5]. Chan RW, Bryant RW. Post-core foundations for endodontically treated posterior teeth. J Prosthet Dent. 1982 Oct;48(4):401-6. Pubmed PMID: 6752384 .

[6]. Cohen BI, Condos S, Deutsch AS, Musikant BL. Fracture strength of three different core materials in combination with three different endodontic posts. Int J Prosthodont. 1994 Mar-Apr;7(2):178-82. Pubmed PMID: 8003200.

[7]. Faria AC, Rodrigues RC, de Almeida Antunes RP, de MattosMda G, Ribeiro RF. Endodontically treated teeth: characteristics and considerations to restore them. J Prosthodont Res. 2011 Apr;55(2):69-74. PubmedPMID: 20709618.

[8]. Fernandes AS, Shetty S, Coutinho I. Factors determining post selection: a literature review. J Prosthet Dent. 2003 Dec;90(6):556-62. Pubmed PMID: 14668756.

[9]. Gu XH, Kern M. Fracture resistance of crowned incisors with different post systems and luting agents. J Oral Rehabil. 2006 Dec;33(12):918-23. Pubmed PMID: 17168934.

[10]. Guzy GE, Nicholls JI. In vitro comparison of intact endodontically treated teeth with and without endo-post reinforcement. J Prosthet Dent. 1979 Jul;42(1):39-44. Pubmed PMID: 379307.

[11]. Hussainy SN, Nasim I, Thomas T, Ranjan M. Clinical performance of resinmodified glass ionomer cement, flowable composite, and polyacid-modified resin composite in noncarious cervical lesions: One-year follow-up. J Conserv Dent. 2018 Sep-Oct;21(5):510-515. Pubmed PMID: 30294112.

[12]. Janani K, Palanivelu A, Sandhya R. Diagnostic accuracy of dental pulse oxi- 
meter with customized sensor holder, thermal test and electric pulp test for the evaluation of pulp vitality: an in vivo study. Brazilian Dental Science. 2020 Jan 31;23(1):8-p.

[13]. Jose J, Subbaiyan H. Different treatment modalities followed by dental practitioners for ellis class 2 fracture-A questionnaire-based survey. The Open Dentistry Journal. 2020 Feb 18;14(1).

[14]. Kumar D, Antony SD. Calcified canal and negotiation-A review. Research Journal of Pharmacy and Technology. 2018 Aug 1;11(8):3727-30.

[15]. Manohar MP, Sharma S. A survey of the knowledge, attitude, and awareness about the principal choice of intracanal medicaments among the general dental practitioners and nonendodontic specialists. Indian J Dent Res. 2018 Nov-Dec;29(6):716-720. Pubmed PMID: 30588997.

[16]. Maroli A, Hoelcher KAL, Reginato VF, Spazzin AO, Caldas RA, Bacchi A. Biomechanical behavior of teeth without remaining coronal structure restored with different post designs and materials. Mater SciEng C Mater Biol Appl. 2017 Jul 1;76:839-844. Pubmed PMID: 28482598.

[17]. Melo MP, Valle AL, Pereira JR, Bonachela WC, Pegoraro LF, Bonfante G. Evaluation of fracture resistance of endodontically treated teeth restored with prefabricated posts and composites with varying quantities of remaining coronal tooth structure. J Appl Oral Sci. 2005 Jun;13(2):141-6. Pubmed PMID: 20924538

[18]. Nandakumar M, Nasim I. Comparative evaluation of grape seed and cranberry extracts in preventing enamel erosion: An optical emission spectrometric analysis. J Conserv Dent. 2018 Sep-Oct;21(5):516-520. Pubmed PMID: 30294113.

[19]. Ng CC, Dumbrigue HB, Al-Bayat MI, Griggs JA, Wakefield CW. Influence of remaining coronal tooth structure location on the fracture resistance of restored endodontically treated anterior teeth. J Prosthet Dent. 2006 Apr;95(4):290-6. Pubmed PMID: 16616126.

[20]. Noor SS. Chlorhexidine: Its properties and effects. Research Journal of Pharmacy and Technology. 2016 Oct 1;9(10):1755.

[21]. Pereira JR, de Ornelas F, Conti PC, do Valle AL. Effect of a crown ferrule on the fracture resistance of endodontically treated teeth restored with prefabricated posts. J Prosthet Dent. 2006 Jan;95(1):50-4. Pubmed PMID: 16399275

[22]. Rajakeerthi R, Nivedhitha MS. Natural Product as the Storage medium for an avulsed tooth-A Systematic Review. Cumhuriyet Dental Journal. 2019;22(2):249-56.

[23]. Rajendran R, Kunjusankaran RN, Sandhya R, Anilkumar A, Santhosh $\mathrm{R}$, Patil SR. Comparative evaluation of remineralizing potential of a paste containing bioactive glass and a topical cream containing casein phosphopeptide-amorphous calcium phosphate: An in vitro study. Pesquisabrasileiraemodontopediatria e clinicaintegrada. 2019;19.

[24]. Ramamoorthi S, Nivedhitha MS, Divyanand MJ. Comparative evaluation of postoperative pain after using endodontic needle and EndoActivator during root canal irrigation: A randomised controlled trial. AustEndod J. 2015 Aug;41(2):78-87. Pubmed PMID: 25195661

[25]. Ramanathan S, Solete P. Cone-beam Computed Tomography Evaluation of Root Canal Preparation using Various Rotary Instruments: An in vitro Study. J Contemp Dent Pract. 2015 Nov 1;16(11):869-72. Pubmed PMID: 26718293.

[26]. Teja KV, Ramesh S, Priya V. Regulation of matrix metalloproteinase-3 gene expression in inflammation: A molecular study. J Conserv Dent. 2018 NovDec;21(6):592-596. Pubmed PMID: 30546201.

[27]. Ravinthar K. Recent advancements in laminates and veneers in dentistry. Research Journal of Pharmacy and Technology. 2018 Feb 1;11(2):785-7.

[28]. Schwartz RS, Robbins JW. Post placement and restoration of endodontically treated teeth: a literature review. J Endod. 2004 May;30(5):289-301. Pubmed PMID: 15107639.

[29]. Siddique R, Sureshbabu NM, Somasundaram J, Jacob B, Selvam D. Qualitative and quantitative analysis of precipitate formation following interaction of chlorhexidine with sodium hypochlorite, neem, and tulsi. J Conserv Dent. 2019 Jan-Feb;22(1):40-47. PubmedPMID: 30820081

[30]. Sidoli GE, King PA, Setchell DJ. An in vitro evaluation of a carbon fiberbased post and core system. J Prosthet Dent. 1997 Jul;78(1):5-9. PubmedPMID: 9237139

[31]. Soares CJ, Valdivia AD, da Silva GR, Santana FR, MenezesMde S. Longitudinal clinical evaluation of post systems: a literature review. Braz Dent J. 2012;23(2):135-740. Pubmed PMID: 22666771.

[32]. Spear F. When to restore, when to remove: the single debilitated tooth. CompendContinEduc Dent. 1999 Apr;20(4):316-8. Pubmed PMID: 11692339.

[33]. Standlee JP, Caputo AA, Hanson EC. Retention of endodontic dowels: effects of cement, dowel length, diameter, and design. J Prosthet Dent. 1978 Apr;39(4):400-5. Pubmed PMID: 347057.

[34]. Teja KV, Ramesh S. Shape optimal and clean more. Saudi Endodontic Journal. 2019 Sep 1;9(3):235.

[35]. Zalkind M, Hochman N. Esthetic considerations in restoring endodontically treated teeth with posts and cores. J Prosthet Dent. 1998 Jun;79(6):702-5. Pubmed PMID: 9627901. 